Document downloaded from:

http://hdl.handle.net/10251/140938

This paper must be cited as:

Bardoulet, L.; Corberán, JM.; Santiago Martínez-Ballester (04-2). How to achieve full liquid conditions at the capillary tube inlet of a household refrigerator. International Journal of Refrigeration. 100:265-273. https://doi.org/10.1016/j.jirefrig.2019.02.006

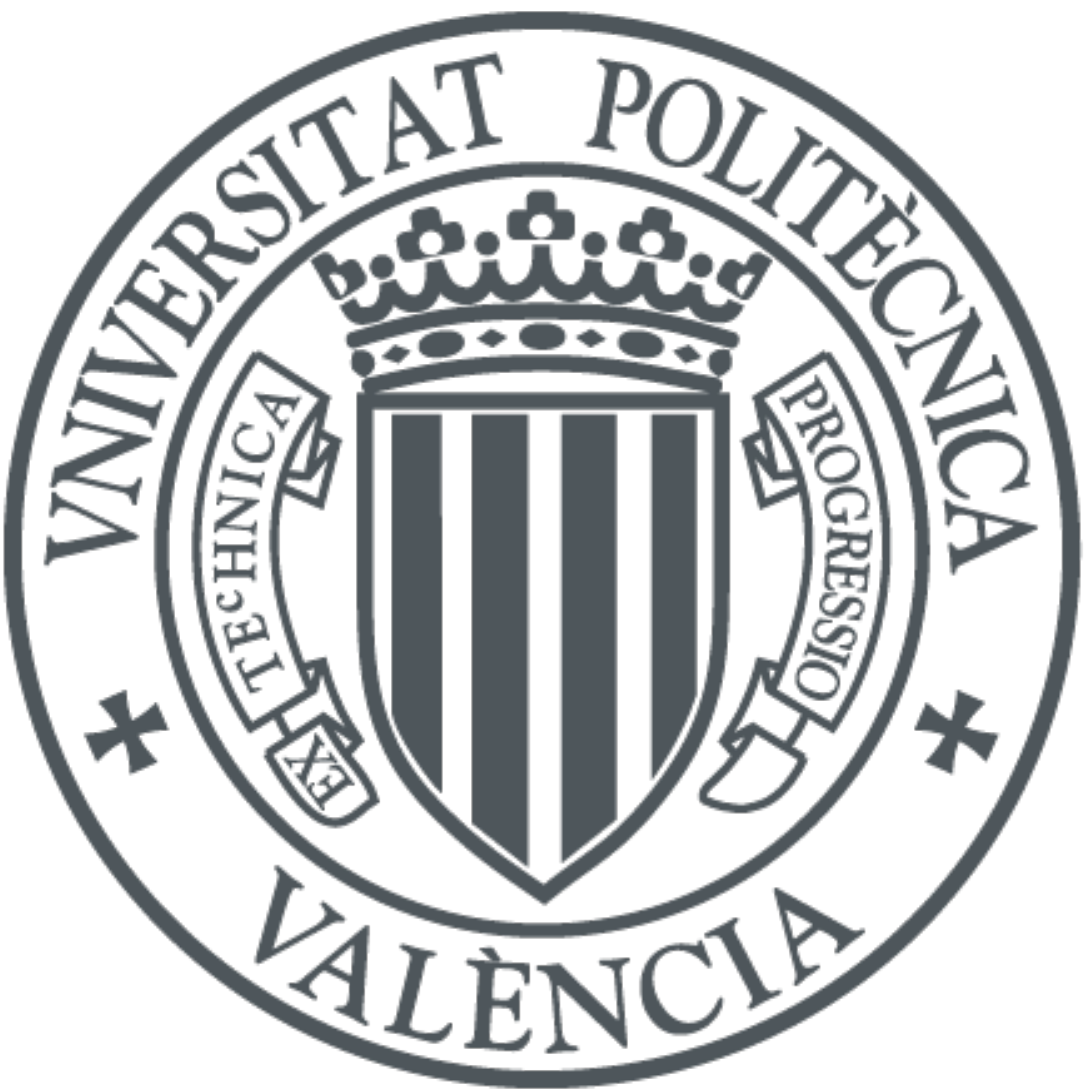

The final publication is available at

https://doi.org/10.1016/j.jirefrig.2019.02.006

Copyright Elsevier

Additional Information 
1

\title{
HOW TO GET FULL LIQUID CONDITIONS AT THE CAPILLARY TUBE INLET OF A HOUSEHOLD REFRIGERATOR
}

Laetitia Bardoulet ${ }^{\left(1,{ }^{*}\right)}$, José M. Corberán ${ }^{(1)}$, Santiago Martínez-Ballester ${ }^{(2)}$,

1) Universitat Politècnica de València, Institute for Energy Engineering, Camino de vera, s/n, Valencia, 46022, Spain

2) Ingersol Rand,

Sant Feliu de Llobregat, 08980, Spain

* Corresponding Author. E-mail address: laetitia.bardoulet@iie.upv.es

\begin{abstract}
Capillary tube with liquid-to-suction heat exchanger is a component widely used in household refrigerators. Recent works have indicated that even when measuring subcooled conditions at the condenser outlet, the actual capillary tube inlet is two phase-flow.

The original refrigerant-to-air condenser of a household refrigerator was replaced by a refrigerant-to-water condenser to assess, from the heat balance between refrigerant and water capacities, the refrigerant conditions at the condenser outlet at the capillary tube inlet. Measurements indicate a non-equilibrium two-phase flow composed of subcooled vapor and liquid at the capillary tube inlet.

The test bench design was modified by using a smaller capillary tube diameter and increasing compressor speed. Full liquid conditions at the capillary tube inlet were reached with this new configuration.

A performance analysis comparison between both the original and the new design reveals that COP were higher in cases of fully liquid conditions at the capillary tube inlet.
\end{abstract}


Keywords: Household refrigerator, capillary tube inlet, refrigerant visualization, non-equilibrium, subcooled vapor, COP

\section{INTRODUCTION}

In household refrigerators, capillary tube with a liquid-to-suction heat exchanger (CTLSHX) is the most widespread expansion device due to its simplicity and low cost. Liquid conditions at the capillary tube inlet are necessary to avoid negative consequences such as noise (Hartmann and Melo, 2013) or hysteresis effect and reduction of CT-LSHX effectiveness (Liu and Bullard, 1997). Another consequence of the absence of liquid at the inlet of the capillary tube is a lower cooling capacity due to a certain decrease in refrigerant mass flow rate, which affects the global efficiency. Subcooled conditions at the capillary tube inlet are always reported in the literature.

Nevertheless, some recent works concluded that the subcooled conditions at the capillary tube inlet may not be real, which, if true, would have consequences for efficiency and, more generally, energy consumption.

Boeng and Melo (2014) performed an experimental study, using a refrigerator-freezer equipped with R600a, to identify the optimal combination of refrigerant charge and capillary tube by varying the expansion device capacity. These researchers then complemented this work by applying a model (Hermes et al., 2008) to examine correlations between degree of valve opening and the equivalent capillary diameter. By visualization of the capillary tube inlet, the authors concluded that even with a subcooling of $5 \mathrm{~K}$, two-phase flow occurred at the inlet. As a possible explanation, Boeng and Melo highlighted that at the capillary inlet, there was a non-equilibrium mixture of subcooled liquid and saturated vapor instead of a purely liquid phase.

Martinez-Ballester et al. (2017), by visualization of the condenser outlet and capillary tube inlet of a household refrigerator filled with R600a, concluded that the capillary tube inlet was twophase flow, although $14 \mathrm{~K}$ of subcooling was measured.

Lee et al. (2016) visualized a two-phase refrigerant flow at the inlet of the capillary tube of a commercial refrigeration system working with isobutane. These researchers set up a transparent 

the vapor and liquid temperatures, as the condensation pressure. This study revealed that the refrigerant was in a non-equilibrium state where both subcooled liquid and subcooled vapor coexisted at the capillary tube inlet. The authors subsequently proposed a method to calculate the enthalpy for non-equilibrium refrigerant conditions and could estimate the vapor quality for different condensing pressures ranging from $2.44 \%$ to $4.29 \%$ at the condenser outlet.

Ko and Jeong (2017) complemented previous work by studying the effect of a nonequilibrium subcooled two-phase flow on the performance of a vapor compression refrigeration system. The authors estimated that the COP may be overestimated by $19.4 \%$ if the thermodynamic properties table is used for a refrigerant non-equilibrium state.

Various explanations are thus provided to explain the presence of two-phase flow at the capillary tube inlet. As stated by Lee et al. (2016), an explanation of the presence of vapor, although a certain subcooling is measured, is the non-equilibrium state of the refrigerant composed of subcooled liquid and subcooled vapor. Whereas Boeng and Melo (2014) proposed non-equilibrium between saturated vapor and subcooled liquid.

In their study, Martinez-Ballester et al. (2017) set up a transparent tube of $1.5 \mathrm{~m}$ at the condenser outlet. The authors stated that the transparent section was relatively long and could be considered adiabatic compared with a normal tube and that the refrigerant had enough length to achieve an equilibrium state or, at least, reveal some evolution towards equilibrium. This study provides a hypothesis for the presence of vapor at the capillary tube inlet: the capillary tube was oversized and therefore, to match the compressor flow rate with the flow rate through the capillary tube, the inlet should have been necessary under two-phase flow conditions so the flow rate was sufficiently low to match compressor flow rate.

The main objectives of this work are first, to determine a fundamental explanation of actual conditions at the capillary tube inlet of a household refrigerator system and second, improve apparatus design to ensure required subcooling and continuously provide liquid at the capillary tube inlet. In order to achieve these goals, four different experimental campaigns have been performed by means of an innovative test bench using a household refrigerator. First, the operating conditions were determined with the original condenser and capillary tube for an optimal charge 
of refrigerant. Second, these operating conditions have been reproduced with a refrigerant-to-water condenser in order to be able to measure the heat produced during the condensation and thus determine the vapor quality or subcooling degree at the capillary tube inlet. Third, a smaller capillary tube has been tested with different compressor speeds in order to fill with liquid the capillary tube inlet. Finally, a performance analysis comparison between a capillary tube inlet composed of vapor and liquid and a capillary tube inlet composed of only liquid was performed.

\section{EXPERIMENTAL SET-UP}

\subsection{Test Bench}

The original apparatus is a high efficiency 2 doors refrigerator-freezer of A+++ energy class, no frost, and working with R600a. It consists of a fin and tube evaporator, a tube and wire condenser, a variable-speed $7 \mathrm{~cm}^{3}$ hermetic reciprocating compressor and a capillary tube with a liquid-to-suction heat exchanger as expansion device.

The original refrigerator was modified in order to test different condensers and capillary tubes configurations (Figure 1). A set of valves allows operating with either the original refrigerant-to-air condenser or a refrigerant-to-water condenser, composed of twin tubes of 3.16 $\mathrm{mm}$ diameter welded on $2.53 \mathrm{~m}$ length and carefully insulated.

In order to visualize the flow, a PFA transparent tube section has been set up at the outlet of each condenser configuration. In the case of the refrigerant-to-air condenser, the ultimate $1.5 \mathrm{~m}$ of the original condenser has been cut off and replaced with the same length of transparent tube. An extra transparent tube section of $0.5 \mathrm{~m}$ has been added to the refrigerant-to-water condenser. Two different capillary tubes are set up in the same suction line: the original one of $0.6 \mathrm{~mm}$ diameter, and a smaller one of $0.55 \mathrm{~mm}$. They are both in a lateral configuration i.e. both capillary tubes are welded to the suction line. They are mounted with a vertical transparent filter of PFA filled with zeolite balls (Figure 1), which allows visualizing the entrance of the capillary tube. A set of valves lets operate with one capillary tube or another.

Figure 1 presents a drawing of the test bench indicating the installed instrumentation: thermocouples, RTDs, mass flow meters and pressure transducers. 


\subsection{Experimental tests campaign procedure}

Table 2 describes the main parameters of the four experimental campaigns. Steady tests were conducted because it is the best way to analyze and understand the refrigerant cycle.

In order to assess the conditions at the capillary tube inlet, experimental campaign 1 dealt with the determination of the operating conditions of the apparatus with both the original condenser and the capillary tube, for an optimal charge of refrigerant. The optimal refrigerant charge was the one that maximized the COP.

Experimental campaign 2 dealt with the use of the water condenser in order to be able to study the actual capillary tube inlet conditions along a wider range of condensation conditions. To do so, the operating conditions previously determined in the first campaign (original air tube and wire condenser) were reproduced using the refrigerant-to-water condenser. The refrigerant charge of the system was increased slowly until operating parameters were very close to the required one. Then, a fine-tuning was done, varying the water mass flow rate from $0.447 \mathrm{~kg} \cdot \mathrm{min}^{-1}$ to 0.066 $\mathrm{kg} \cdot \mathrm{min}^{-1}$ in order to match almost exactly the target operating conditions. The measurement of the heat exchanged during the condensation process allowed for the estimation of the vapor quality or degree of subcooling at the capillary tube inlet. 
The aim of experimental campaign 3 was to search for other possible balance points for the matching between the capillary tube design (diameter) and compressor speed in which the inlet of the capillary tube was continuously kept under liquid conditions. To do so, a $0.55 \mathrm{~mm}$ capillary tube diameter instead of the original $0.6 \mathrm{~mm}$ tube, and different compressor speeds were tested. It should be pointed out that full liquid conditions could not be obtained with the original capillary tube at maximum compressor speed.

To assess if the performance obtained with the improved design determined in experimental campaign 3 (higher compressor speed and smaller capillary tube) was better than the original design, a fourth experimental campaign was carried out using two capillary tubes of different diameters $(0.55 \mathrm{~mm}$ and $0.6 \mathrm{~mm})$ at the same compressor speed. The COP were determined by determining the optimal refrigerant charge of each capillary tube size, with the same compressor speed (2900 rpm).

\section{RESULTS AND DISCUSSION}

\subsection{Optimal charge of the refrigerator with the original condenser}

In order to determine the optimal refrigerant charge, a charge variation study was performed. Charge was varied from $74.5 \mathrm{~g}$ to $90 \mathrm{~g}$. Results with $90 \mathrm{~g}$ are not included in the data analysis because suction became frozen, and therefore, it was not possible to reach the required temperature inside the cabinets. The temperature inside the FF and FZ were maintained constant by a PID regulating the maximum power of a $200 \mathrm{~W}$ heater inside each cabinet. Average temperature inside the FF and the $\mathrm{FZ}$ was respectively equal to $4^{\circ} \mathrm{C}$ and $-18^{\circ} \mathrm{C}$. The optimal charge is that which maximized COP.

The cooling capacity, considering the presence of the CT-LSHX, was calculated as per Eq 3.1.

$$
\dot{Q}_{\text {cool }}=\dot{m}_{\text {ref }}\left(h_{\text {suct }}-h_{\text {condouT }}\right)
$$

The COP was calculated as per Eq. 3.2. 

Figure 2 presents the cooling capacity calculated from the refrigerant side, measured compressor power and corresponding COP and its uncertainty. The compressor power increased almost linearly with the refrigerant charge and in a proportion equal to $14 \%$ from the lowest to the highest refrigerant charge. The cooling capacity increased when the charge increased but reached a maximum of around $82 \mathrm{~g}$ and then started to decrease. This saw the COP have first a moderate increase with refrigerant charge, a maximum around $80 \mathrm{~g}$, and then a decrease with a significant negative slope. Similar results can be found in the literature (Boeng and Melo, 2014; Choi and Kim, 2002).

During the entire campaign, visualizations of the condenser outlet and capillary tube inlet confirmed the presence of two-phase flow.

To more easily and accurately reproduce the target operating conditions obtained for $80 \mathrm{~g}$ (optimal refrigerant charge) with the refrigerant-to-water condenser, the refrigerant circuit was again charged (maintaining the air condenser and original capillary tube) with the optimal charge and a test was run which only regulated the FF (fresh food cabinet) temperature, i.e., without the heater in the FZ (freezer cabinet) because the heater value required to reach the target conditions was approximately $0 \mathrm{~W}$.

\subsection{Assessment of the subcooling from the heat balance at the waterside}

In experimental campaign 2 , the original air condenser was replaced by the water condenser in order to be able first, to have a larger potential for the variation of the condensation conditions, and second, to assess, from the heat balance at the water side of the condenser, the refrigerant conditions at the outlet and therefore, at the inlet of the capillary tube. Average temperature inside the $\mathrm{FF}$ was equal to $4{ }^{\circ} \mathrm{C}$. FZ temperature was not regulated for the reasons mentioned in the previous section.

The refrigerant conditions at the condenser outlet have been calculated using the heat balance between water heat capacity (Eq. 3.3) and refrigerant condensing capacity (Eq. 3.4). 


$$
\begin{gathered}
\dot{Q}_{w}=\dot{m}_{w} c_{p_{w}}\left(T_{\text {wOUT }}-T_{\text {wIN }}\right) \\
\dot{Q}_{w}=\dot{Q}_{\text {cond }}=\dot{m}_{\text {ref }}\left(h_{\text {condIN }}-h_{\text {condoUT_HX }}\right)
\end{gathered}
$$

From Eqs 3.3 and 3.4, it is possible to calculate the enthalpy at the condenser outlet (Eq. $3.5)$ :

$$
h_{\text {condouT_HX }}=h_{\text {condIN }}-\frac{\dot{m}_{w}}{\dot{m}_{\text {ref }}} c_{p_{w}}\left(T_{\text {wOUT }}-T_{\text {wIN }}\right)
$$

Calculations of the different parameter uncertainties were carried out using the software EES.

Figure 3 compares the water heat capacity represented regarding water mass flow rate and evaluated from the waterside measurements $\left(\dot{Q}_{w}\right)$ and condensing capacity calculated from the refrigerant side using the enthalpy calculated with pressure and temperature $\left(\dot{\mathrm{Q}}_{\text {cond }}\right)$ with their associated uncertainties (hardly visible because of their low values). There are two possible reasons for the differences between $\dot{\mathrm{Q}}_{\text {cond }}$ and $\dot{\mathrm{Q}}_{\mathrm{w}}$. First, the refrigerant mass flow rate measurement could be less accurate than expected because of variations in oil concentration or influence of the oil on the measurement, which is unknown. Second, an assumption of thermodynamic equilibrium at the refrigerant outlet for the evaluation of the condensing capacity ( $\left.\dot{Q}_{\text {cond }}\right)$ as found out by Ko and Jeong (2017).

In general, it was observed that the water heat capacity was always lower than the refrigerant capacity and that the uncertainty of the measurements could not explain this difference. Both capacities remained constant for water mass flow rates from $0.447 \mathrm{~kg} \cdot \mathrm{min}^{-1}$ to $0.252 \mathrm{~kg} \cdot \mathrm{min}^{-}$ ${ }^{1}$, then continually decreased if the water flow rate decreased. When the water mass flow rate decreased, the capacity of the condenser to reject the heat to the water also decreased, and therefore, the condensation temperature had to increase, also increasing condensation pressure. At some point, the rise in pressure ratio leads to a decline in the refrigerant mass flow rate. This resulted in the observed decrease of both capacities. 
Figure 4 depicts the corresponding subcooling, evaluated first from the pressure and temperature measurements and assuming thermodynamic equilibrium for the refrigerant, namely $\mathrm{SC}_{\mathrm{pT}}$, and second, the subcooling evaluated from the condenser inlet conditions and waterside measured heat, namely $\mathrm{SC}_{\mathrm{HX}}$.

$\mathrm{SC}_{\mathrm{pT}}$ was almost constant around $9 \mathrm{~K}$, except for the lowest tested water flow rate, where it decreased to $7 \mathrm{~K}$. These subcooling values contradicted the visualization of flow at the capillary tube inlet, which clearly exhibited two-phase flow conditions, or at least, alternating liquid/ vapor inlet conditions during the entire campaign (Figure 5.a). Martinez et al. (2017) already noted this contradiction between the apparent subcooled state and actual visible conditions of the refrigerant at the capillary tube inlet, with the liquid level always appearing at the capillary inlet mouth.

In contrast with the almost constant value of the $\mathrm{SC}_{\mathrm{pT}}$ subcooling, $\mathrm{SC}_{\mathrm{HX}}$ subcooling was much lower and decreased with the decrease of water flow rate, until reaching a point where subcooling ceased. For a water mass flow rate of $0.066 \mathrm{~kg} \cdot \mathrm{min}^{-1}$ and $0.118 \mathrm{~kg} \cdot \mathrm{min}^{-1}$, the evaluated vapor quality was equal to $8.8 \%$ and $1.7 \%$, respectively. The target values determined in experimental campaign 1 were located between two working points corresponding to water mass flow rates between $0.118 \mathrm{~kg} \cdot \mathrm{min}^{-1}$ and $0.190 \mathrm{~kg} \cdot \mathrm{min}^{-1}$, where a transition in refrigerant conditions was observed. Indeed, a subcooling of $2.5 \mathrm{~K}$ was evaluated with a water mass flow rate of 0.190 $\mathrm{kg} \cdot \mathrm{min}^{-1}$, while $1.7 \%$ vapor quality was found with $0.118 \mathrm{~kg} \cdot \mathrm{min}^{-1}$.

Note that despite the attention paid to instrumentation selection, the analysis of the propagation error reveals that it was challenging to have low uncertainty for $\mathrm{SC}_{\mathrm{HX}}$ subcooling evaluation. From these results, and others reported in the literature, it is clear that it is difficult to conclude which is the actual state of the refrigerant at the capillary tube inlet. Visual observation confirmed the reported alternating vapor-liquid entrance for all performed tests (Figure 5.a). Video recording with a high-speed camera clearly showed the formation of a swirl with small but continuous variations in liquid level and entering conditions. Despite the water mass flow rate variation and thus, very different condensing conditions, it was not possible to fill the inlet of the capillary tube with liquid. Nevertheless, variations in condensing temperature were visible at the condenser outlet, which strongly modified the flow pattern as the water mass flow rate changed, 
resulting in a higher presence of vapor phase for lower water mass flow rate, and thus, higher condensation pressure. Figure 5.b shows the flow pattern at the outlet of the condenser.

The heat balance methodology indicated that, except for the two lowest flow rates, all others indicated a certain low subcooling (around $3 \mathrm{~K}$ ). Pressure and temperature measurements revealed a much higher subcooling. Furthermore, the vapor temperature measured above the filter dryer, which acts as a vapor/liquid separator, was always below the saturation temperature, and practically at the same temperature than the subcooled liquid.

The authors do not find an explanation for the measured refrigerant state since the condensation process happens quite slowly and therefore, the vapor bubbles have time enough to condensate along the tube or inside the filter dryer small volume, or at least keep close to the corresponding saturation temperature (Martínez-Ballester et al., 2017). However, all measurements clearly indicated subcooled conditions for both liquid and vapor, and visualization of the inlet of the capillary tube revealed the entrance of vapor and liquid. Lee et al. (2016) and Ko and Jeong (2017) have observed this paradoxical state and attributed it to non-equilibrium conditions of the flow where both subcooled gas and subcooled liquid coexist.

Regarding the possible effect of oil in the reported phenomena, a reasonable oil ratio in the circulating fluid would have a small impact on condensation temperature. Furthermore, Lee et al. (2016) and Ko and Jeong (Ko and Jeong, 2017) have performed their experiments with an oil separator at the compressor outlet but the difference between $\mathrm{h}_{\text {condOUT-pt }}$ and $\mathrm{h}_{\text {condOUT-HX remained }}$ high, as depicted in Figure 6.

From these considerations, it can be concluded that refrigerant conditions at the capillary tube inlet may have been in a non-equilibrium two-phase flow composed of subcooled liquid and subcooled vapor. Consequently, the enthalpy at the condenser outlet can thus not be determined using the thermodynamic properties table, which is only valid for an equilibrium condition of the refrigerant. 


\subsection{Design improvement to get full liquid conditions at the capillary tube inlet}

A possible explanation for the permanent existence of vapor at the capillary tube entrance is that the capillary tube was oversized and therefore, the refrigerant conditions at the inlet of the capillary must be necessarily under two-phase flow conditions to match the compressor flow rate with the one through the capillary tube.

This potential situation is depicted in Figure 7 where the compressor flow rate is characterized by a line with a negative slope, since it decreases with the pressure ratio increase. A line with positive slope represents the flow rate through the capillary tube, which increases with the pressure ratio. The curves present a qualitative and orientative situation and are not quantitatively representative of actual operation. The balance point, the intersection of these two lines, represents the stable operation point in which the refrigerant flow rate through the compressor matches the one through the capillary tube. The flow rate through the capillary tube with two-phase flow inlet is marked with a dashed line, whereas the zone inlet with liquid refrigerant is indicated by a solid line. As depicted in Figure 7, the balance requires that the flow through the capillary tube is in average in two-phase conditions. This could be the reason why a swirl is observed with a combination of liquid and vapor, or a certain alternating liquid-vapor inlet, at the entrance of the capillary tube.

This argument accounts for the presence of vapor at the capillary tube inlet and leads to the conclusion that the capillary tube is oversized for this refrigerator.

A third experimental campaign was therefore performed, in which the capillary tube was changed to a smaller size $(0.55 \mathrm{~mm}$ diameter) and the compressor speed was varied from 1800 rpm to $3500 \mathrm{rpm}$ in order to be able to find a balance point in which the inlet of the capillary tube could be full of liquid. During this experimental campaign, the tests were run only with the freezer (i.e. the damper between refrigerator and freezer was kept closed) because the purpose was not to analyse a commercial refrigerator anymore, but to focus on the possibility of filling the capillary tube only with liquid. To regulate the temperature in the freezer and ensure the same temperature conditions for the entire test campaign, the previous PID and heater set up was modified. The thermocouple used by the PID was placed at the evaporator air inlet. This type of control insured that the conditions of the secondary fluid at the evaporator inlet were always the same for each 
operating parameter to be tested, despite the variation of cooling capacity produced by the variation of the compressor speed. The air temperature at the evaporator inlet $\mathrm{T}_{\text {air_EvapIN }}$ of a household refrigerator is composed of a mix of air coming from the FF compartment $\left(\mathrm{T}_{\mathrm{FF}}\right)$ and air coming from the FZ compartment $\left(\mathrm{T}_{\mathrm{FZ}}\right)$. Eq. 4.1. allows the evaluation of the corresponding mixing temperature:

$$
T_{\text {air_EvapIN }}=\alpha T_{F F}+(1-\alpha) T_{F Z}
$$

Where $\alpha$ represents the air flow ratio supplied to the FF cabinet. This air flow ratio is usually between 0 and $30 \%$. In the following experimental campaign, $T_{\text {air_EvapIN }}$ has been fixed to $-13.5^{\circ} \mathrm{C}$, which corresponds to an airflow ratio of $20 \%$.

As expected, tests with the smaller diameter capillary tube at 2500 and $3500 \mathrm{rpm}$ led to a filter full of liquid as depicted in Figure 8.a. All transparent parts of the filter were full of liquid and these conditions were maintained all along these tests. Test at $1800 \mathrm{rpm}$ resulted in an alternation between two different liquid level situations at the capillary tube inlet: a liquid level about $5 \mathrm{~mm}$ above the capillary tube inlet (Figure 8.b) without vapor inlet and a swirl with twophase inlet (Figure 8.c).

Visualization of the condenser outlet (Figure 8.d) allows clear observation of the void fraction at the outlet of the condenser for several compressor speeds. As it can be clearly observed, the highest the compressor speed, the lower the void fraction.

Figure 9 shows the results of the evaluation of the subcooling by the two employed methods for the $0.55 \mathrm{~mm}$ diameter capillary tube. As it can be observed, both methods indicate subcooling conditions at $1800 \mathrm{rpm}$ when the visualization shows two phase flow inlet, as revealed by experimental campaign 2. Interestingly, the subcooling $\mathrm{SC}_{\mathrm{pT}}$ is still higher than the one obtained from the heat balance $\mathrm{SC}_{\mathrm{HX}}$, although the differences are smaller. Furthermore, when full liquid conditions are clearly visible, the difference starts to fall inside the uncertainty band. 


\subsection{Performance with the improved design}

The objective of the experimental campaign 4 was to determine whether there is a performance difference between the original design with the capillary tube of $0.6 \mathrm{~mm}$ diameter and the modified design with a slightly lower diameter. The comparison had to be performed at the same compressor speed to compare similar capacities. We selected for this comparison a compressor speed high enough (2900 rpm) to lead to full liquid inlet conditions at the inlet of the $0.55 \mathrm{~mm}$ diameter capillary tube.

Both designs being different, the COP should be determined at their corresponding optimal charge in order to make a fair comparison. Therefore, an optimization charge study was performed for each capillary tube. Figure 10 shows the obtained COP results. As it can be observed, all COP values obtained with the $0.55 \mathrm{~mm}$ diameter capillary tube were higher than those obtained with the $0.6 \mathrm{~mm}$ tube. The average COP difference between the two capillary tubes was around $4 \%$, which is an important performance improvement in this kind of equipment. This indicates that the original capillary tube was slightly oversized.

Regarding the refrigerant visualizations at the capillary tube inlet, the different liquid levels for the different refrigerant charges tested are depicted in Figure 10. As expected, for the $0.6 \mathrm{~mm}$ capillary tube, the inlet was always two-phase flow, as represented in the bottom frame. For the $0.55 \mathrm{~mm}$ capillary tube, different liquid levels were obtained through the refrigerant charge test campaign and are represented in the top frames. For $67.5 \mathrm{~g}$, the filter was full of liquid and the highest COP was found at exactly this refrigerant charge. For the rest of the refrigerant charges tested, the inlet was alternating two-phase flow with mostly liquid inlet.

\section{CONCLUSIONS}

Instead of the original refrigerant-to-air condenser of the refrigerator, a refrigerant-to-water heat exchanger was installed to assess the refrigerant conditions at the capillary tube inlet, from heat balance at the water side of the condenser. Results indicated that, except for the two lowest water mass flow rates tested, all others revealed a certain low subcooling. Nevertheless, it must be 
mentioned that despite considerable effort in selecting accurate instrumentation, uncertainty on the measured results was high.

The pressure and temperature measurements revealed a much higher subcooling, which contradicted the visualization at the capillary tube inlet. Furthermore, the vapor temperature measured above the filter dryer was always practically at the same temperature than the subcooled liquid.

This paradoxical phenomenon was attributed to the presence of non-equilibrium two-phase flow composed of subcooled liquid and subcooled vapor at the capillary tube inlet. Other authors have observed the same paradoxical phenomenon (Ko and Jeong, 2017; Lee et al., 2016). The enthalpy at the condenser outlet can thus not be determined using the thermodynamic properties table, which is only valid for an equilibrium condition of the refrigerant.

The presence of vapor at the capillary tube inlet can be explained by the capillary tube being oversized with respect to the compressor. By increasing the compressor speed from 1600 $\mathrm{rpm}$ to $2500 \mathrm{rpm}$ and reducing the capillary tube diameter from $0.6 \mathrm{~mm}$ to $0.55 \mathrm{~mm}$, it was possible to fill the filter with liquid refrigerant, which resulted impossible with the original capillary tube. It has thus been demonstrated that a non-matching existed between the capillary tube size and the compressor displacement of this commercial household refrigerator.

The transparent tube set up at the condenser outlet revealed that the higher the compressor speed, the lower the void fraction. At the highest compressor speeds, the filter was clearly full of liquid and the void fraction upstream, in the condenser outlet, was almost negligible. That said, the difference between the two subcooling measurements, e.g., $\mathrm{SC}_{\mathrm{pT}}$ and $\mathrm{SC}_{\mathrm{HX}}$, persisted but significantly decreased.

To compare the potential performance improvement of a capillary tube with liquid inlet to a capillary tube with two-phase flow inlet, an experimental campaign was carried out using two capillary tubes of different diameters $(0.55 \mathrm{~mm}$ and $0.6 \mathrm{~mm})$ at the same compressor speed (2900 $\mathrm{rpm}$ ). The COP analysis seems to confirm that liquid at the capillary tube inlet leads to significant better performance than two-phase flow inlet, with an approximate COP increase of around $4 \%$. 


\section{ACKNOWLEDGEMENTS}

The work of Laetitia Bardoulet in this project was partially supported by Santiago Grisolía 2015 program which is funded by the Generalitat Valenciana with reference number GRISOLIA/2015/021.

\section{REFERENCES}

Boeng, J., Melo, C., 2014. Mapping the energy consumption of household refrigerators by varying the refrigerant charge and the expansion restriction. Int. J. Refrig. 41, 37-44. https://doi.org/10.1016/j.ijrefrig.2013.06.005

Choi, J.M., Kim, Y.C., 2002. The effects of improper refrigerant charge on the performance of a heat pump with an electronic expansion valve and capillary tube. Energy 27, 391-404. https://doi.org/10.1016/S0360-5442(01)00093-7

Hartmann, D., Melo, C., 2013. Popping noise in household refrigerators: Fundamentals and practical solutions. Appl. Therm. Eng. 51, 40-47. https://doi.org/10.1016/j.applthermaleng.2012.08.054

Hermes, C.J.L., Melo, C., Gonçalves, J.M., 2008. Modeling of non-adiabatic capillary tube flows: A simplified approach and comprehensive experimental validation. Int. J. Refrig. 31, 1358-1367. https://doi.org/10.1016/j.ijrefrig.2008.04.002

Ko, J., Jeong, J.H., 2017. Effects of a non-equilibrium two-phase refrigerant flow at subcooled temperatures on the performance of an R-600a refrigeration system. Int. J. Refrig. https://doi.org/10.1016/j.ijrefrig.2017.10.029

Lee, W.-J., Seo, J.-Y., Ko, J., Jeong, J.H., 2016. Non-equilibrium two-phase refrigerant flow at subcooled temperatures in an R600a refrigeration system. Int. J. Refrig. 70, 148-156. https://doi.org/10.1016/j.ijrefrig.2016.07.005 
Liu, Y., Bullard, C.W., 1997. An Experimental and Theoretical Analysis of Capillary Tube-Suction Line Heat Exchangers. University of Illinois. Project reference: ACRC TR-109

Martínez-Ballester, S., Bardoulet, L., Pisano, A., Corberán, J.M., 2017. Visualization of refrigerant flow at the capillary tube inlet of a high-efficiency household refrigerator. Int. J. Refrig. 73, 200-208. https://doi.org/10.1016/j.ijrefrig.2016.09.019 


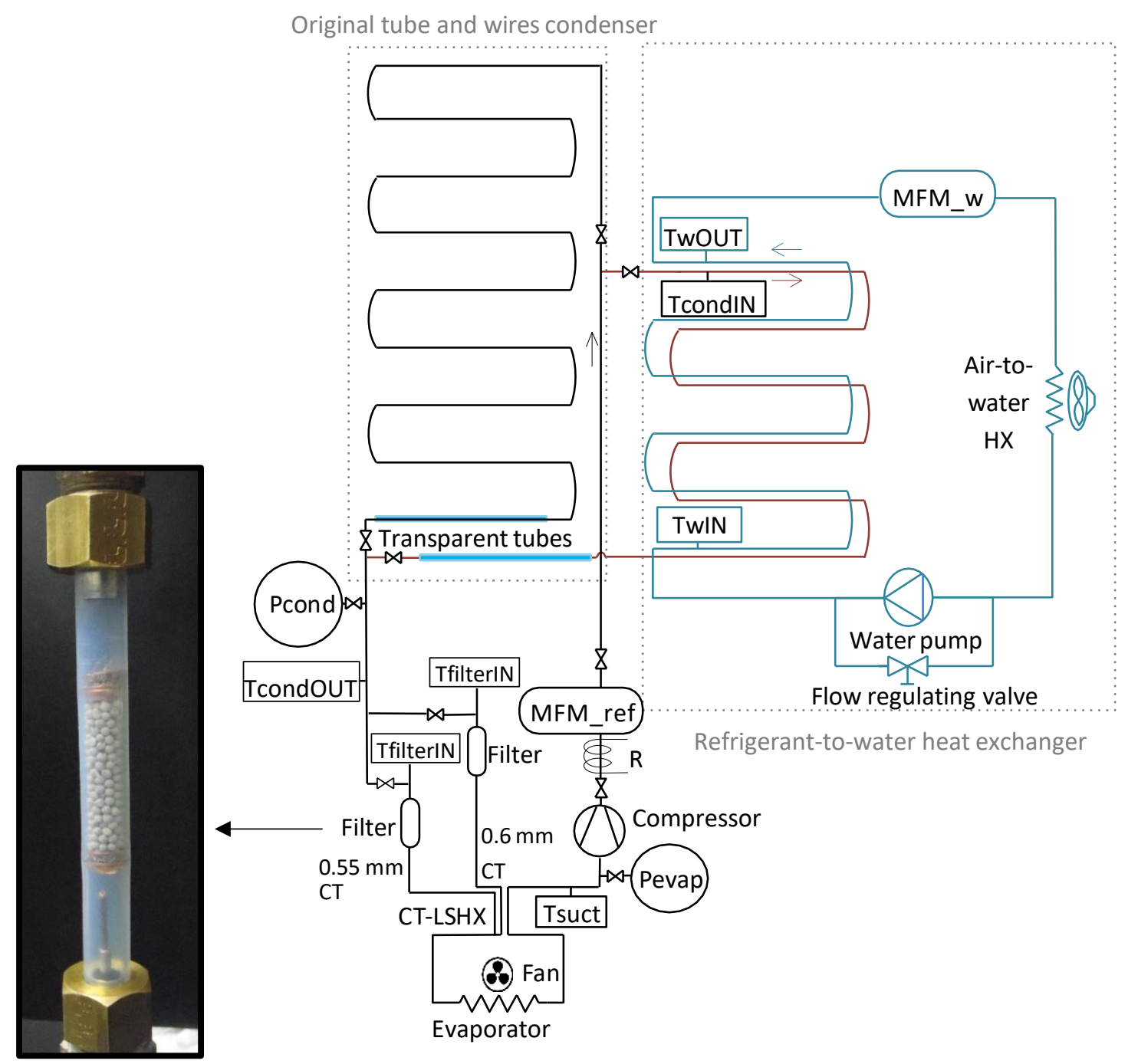

Figure 1: Test bench 


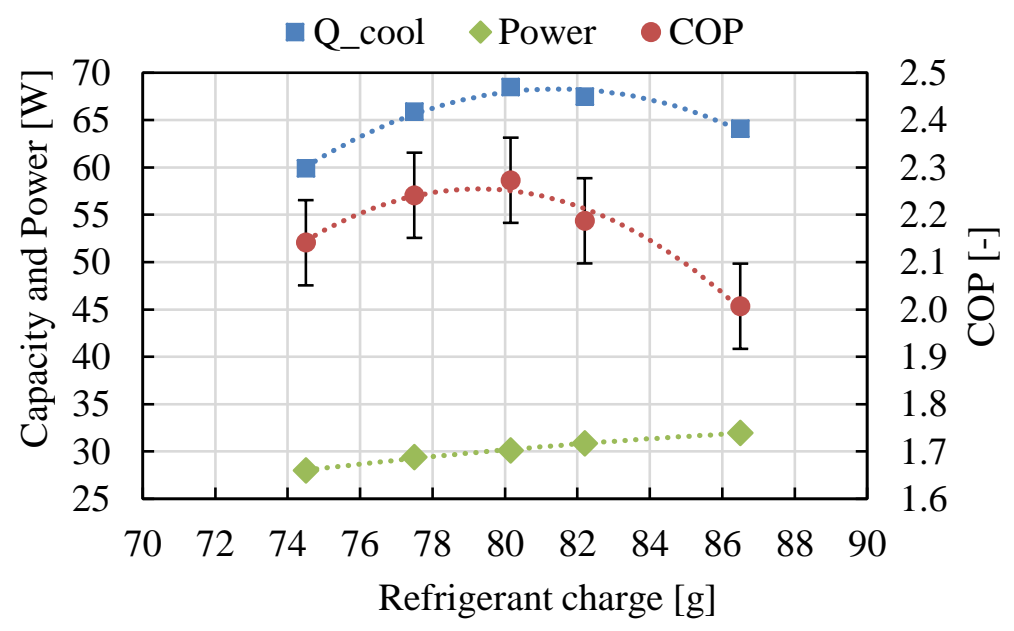

Figure 2: Cooling capacity, COP, and compressor power input for different refrigerant charges 


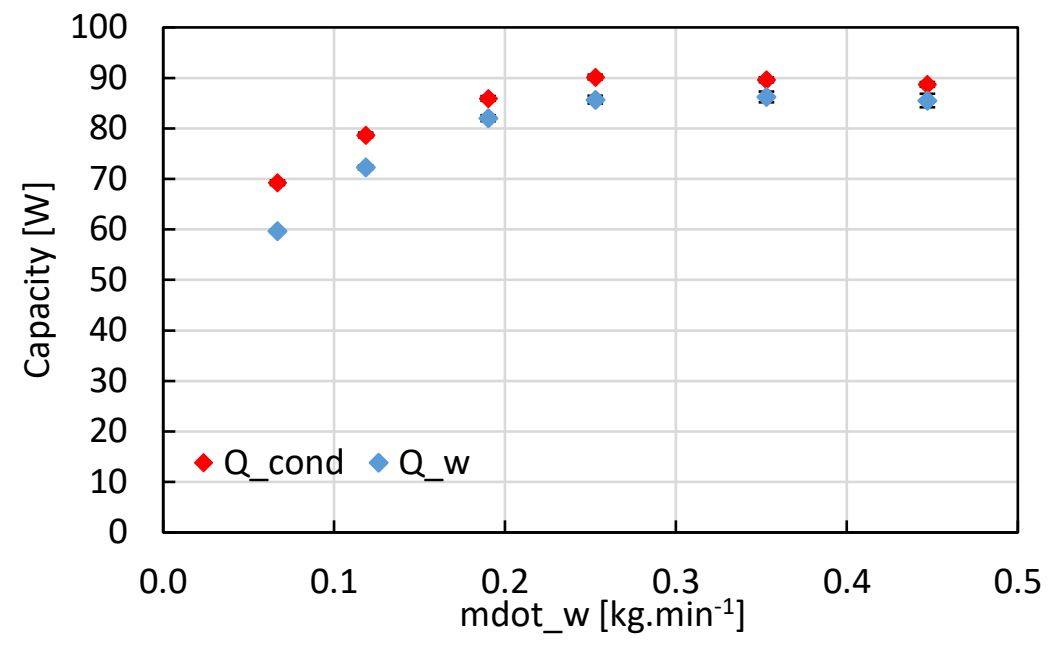

Figure 3: Water side and refrigerant side evaluated capacities varying water mass flow rate though the condenser 


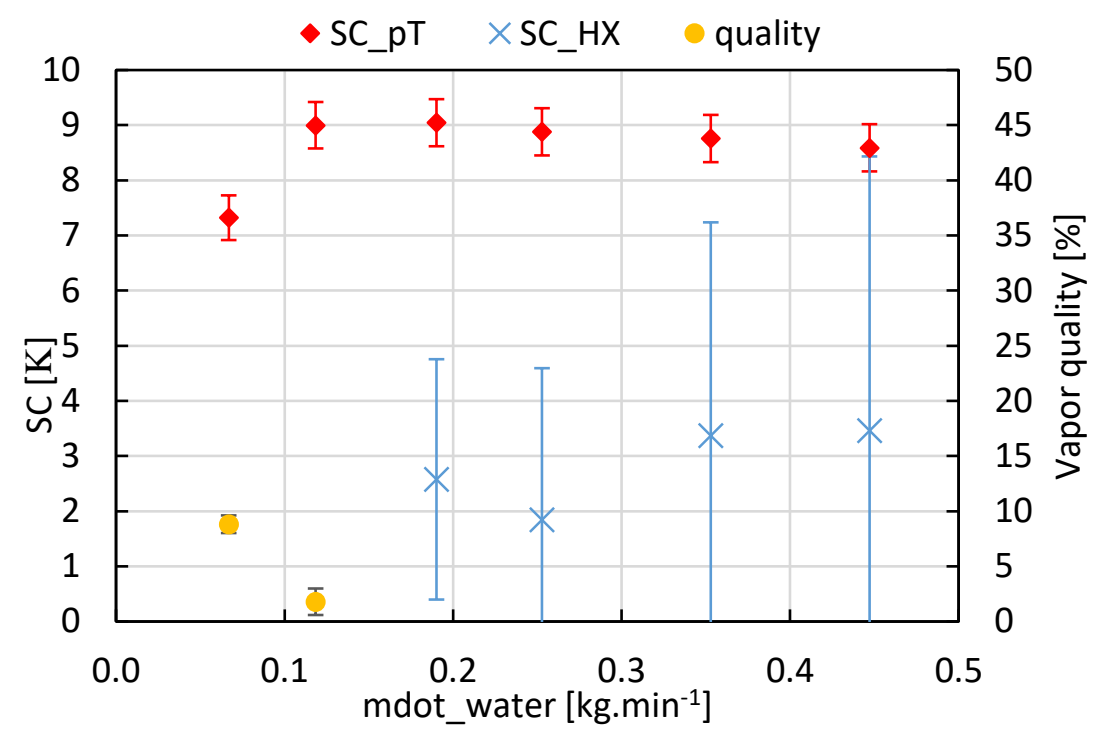

Figure 4: Subcooling evaluated from the pressure and temperature measurements and the assumption of thermodynamic equilibrium, and subcooling evaluated from the inlet refrigerant conditions and the heat measured at the condenser water side. 


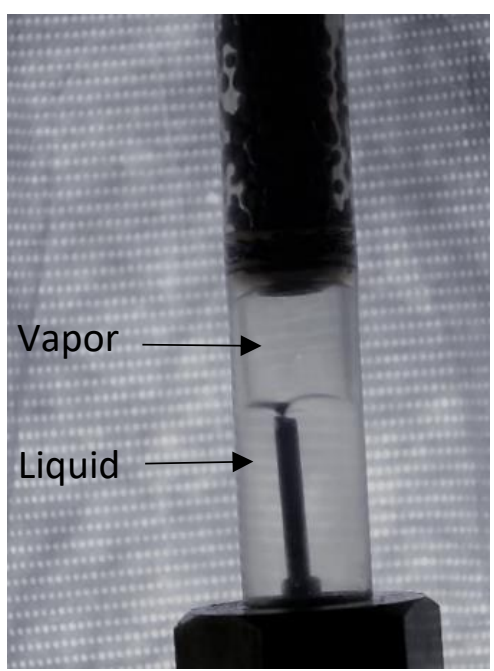

a) Two-phase flow capillary tube inlet

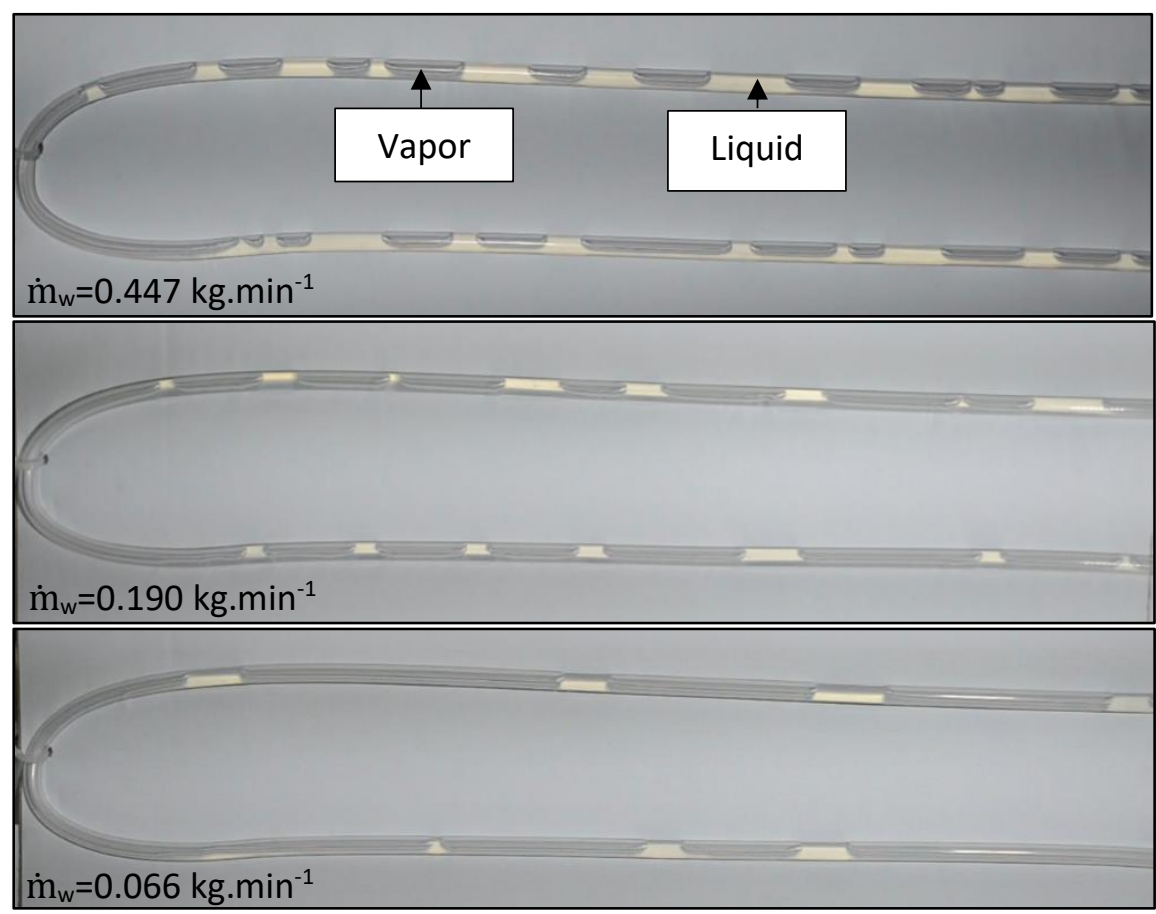

b) Condenser outlet picture for different compressor speeds

Figure 5 : Visualizations of filter inlet and condenser outlet during experimental campaign 2 


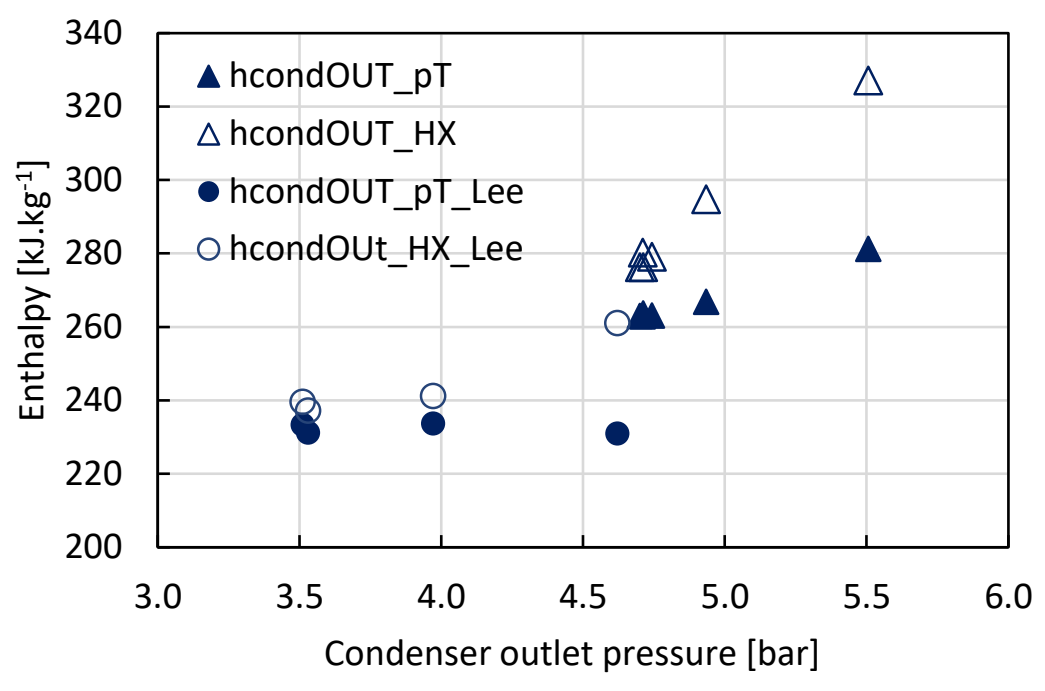

Figure 6: Enthalpies evaluated from the pressure and temperature measurements and the assumption of thermodynamic equilibrium (pT), and enthalpy evaluated from the inlet refrigerant conditions and the heat measured at the condenser water side (HX) compared with data extracted from Lee et al. (2017). 


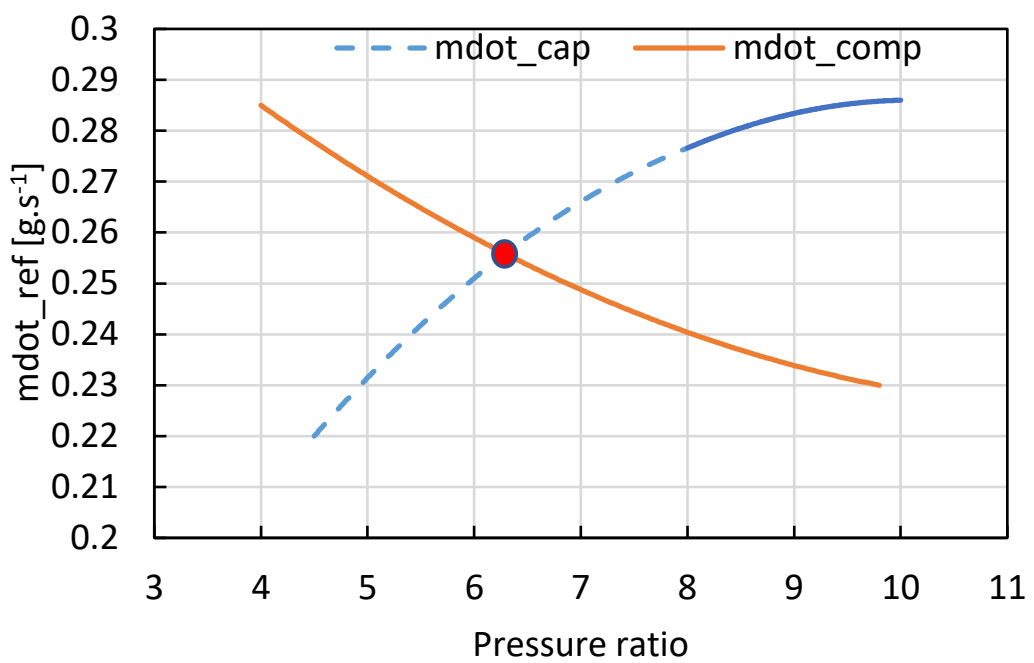

Figure 7: Balance point between the compressor mass flowrate and the mass flowrate through the capillary tube 


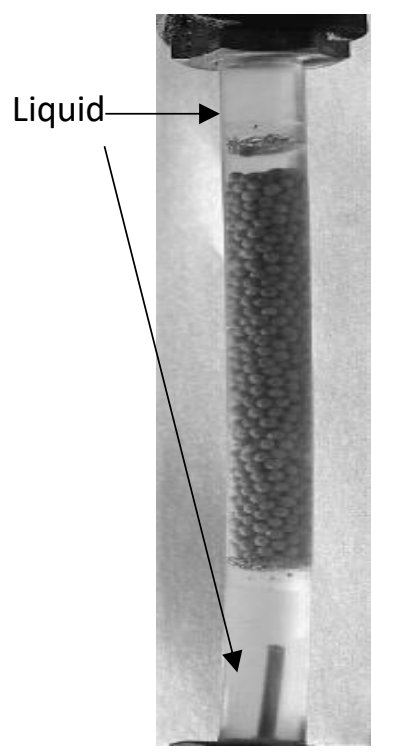

a) Liquid inlet at $2500 \mathrm{rpm}$ and $3500 \mathrm{rpm}$

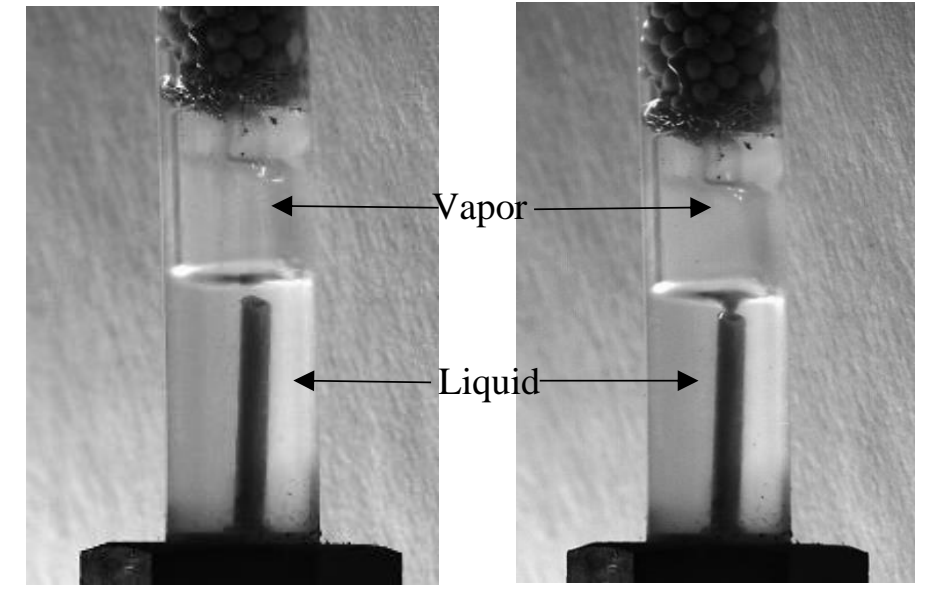

b) Liquid inlet at $1800 \mathrm{rpm}$

c) Two-phase flow liquid inlet at $1800 \mathrm{rpm}$

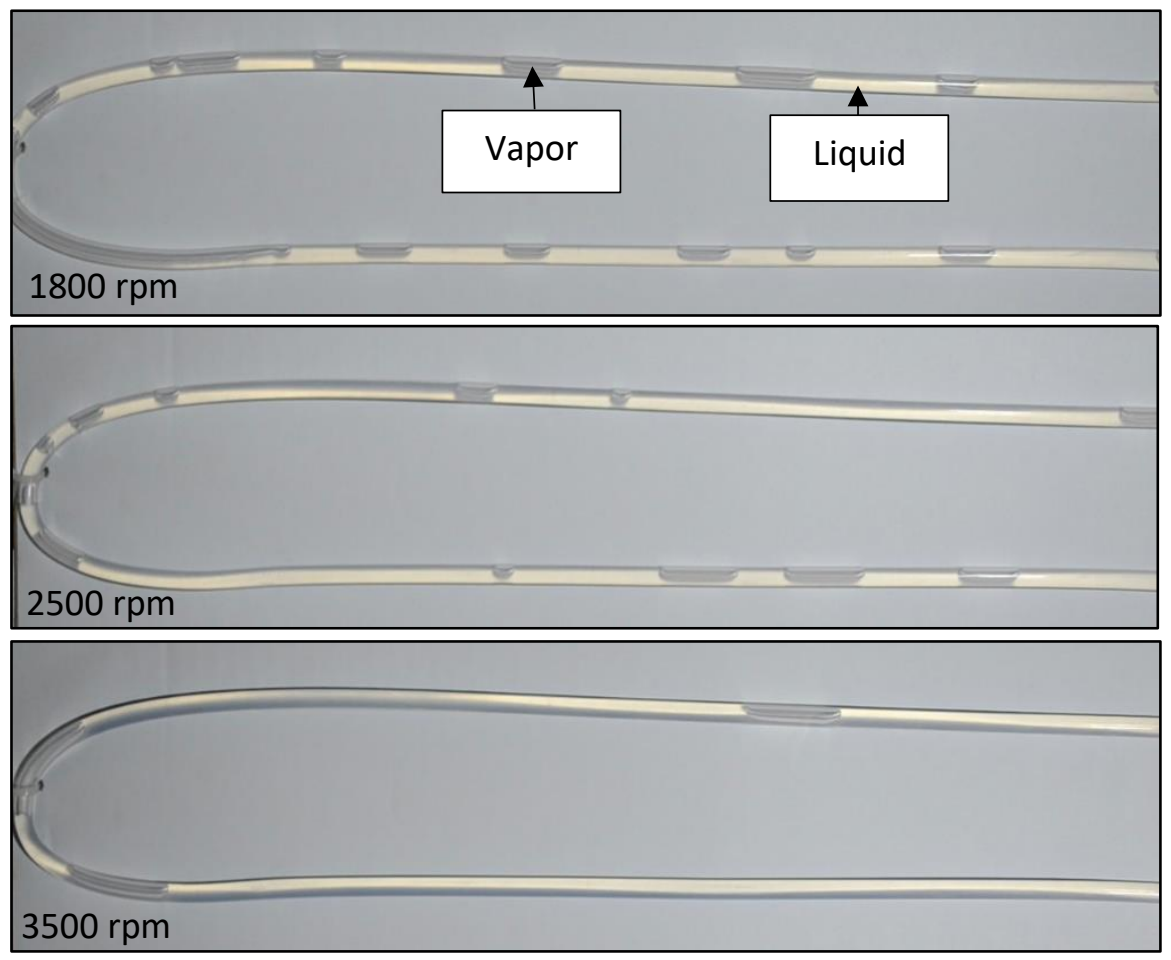

d) Condenser outlet picture for different compressor speeds

Figure 8 : Visualizations of filter inlet and condenser outlet during experimental campaign 3 


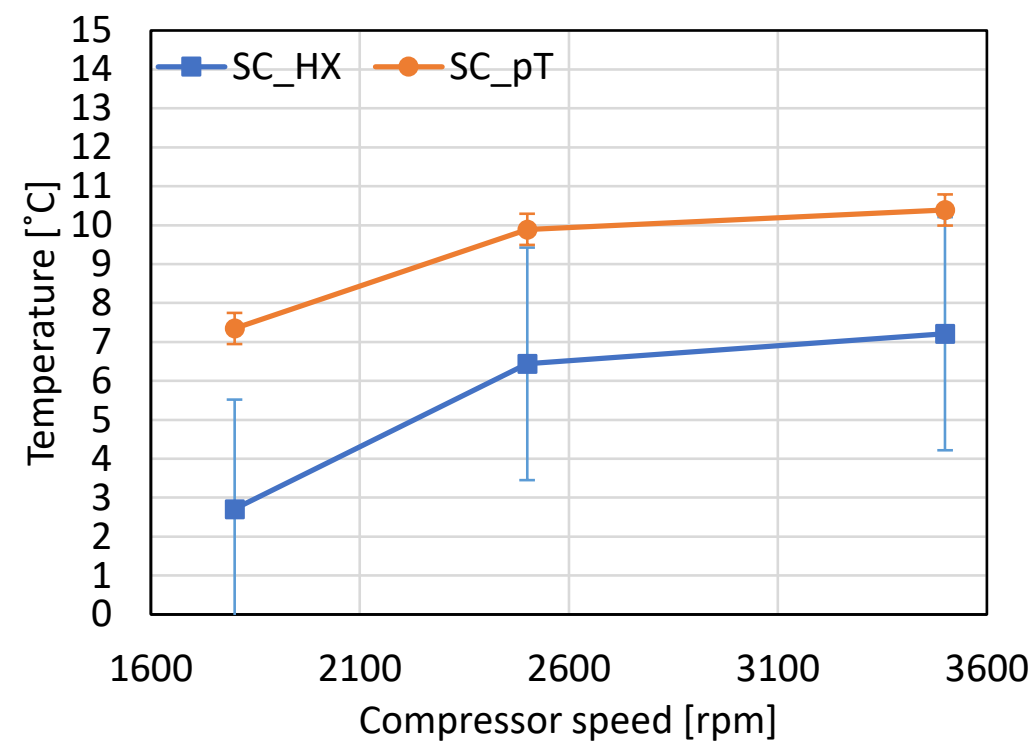

Figure 9: Subcooling evaluated from the pressure and temperature measurements (pT) and the assumption of thermodynamic equilibrium, and subcooling evaluated from the inlet refrigerant conditions and the heat measured on the condenser water side (HX) for different compressor speeds 


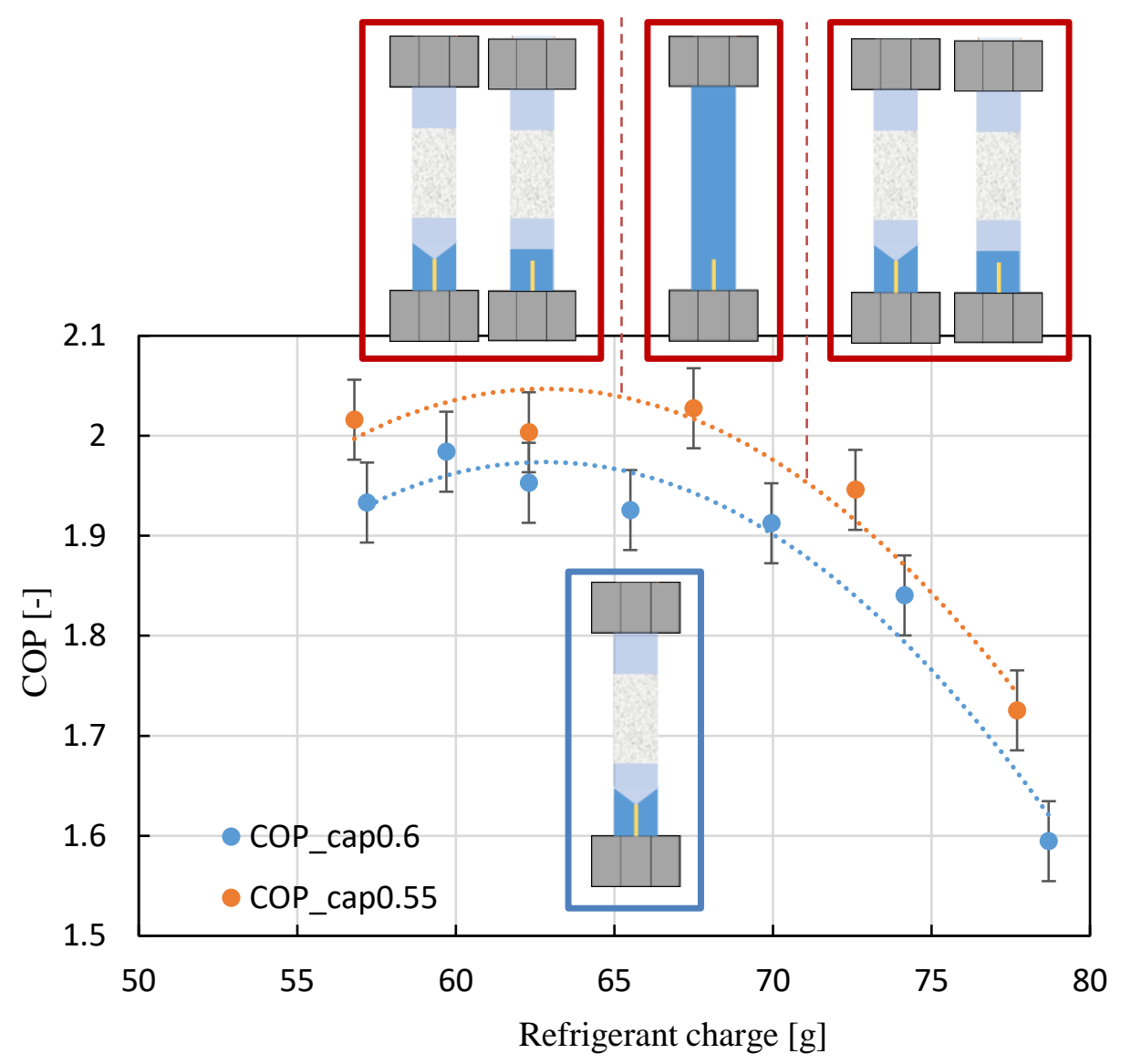

Figure 10: COP and liquid level inside the inlet filter for different refrigerant charges for the two tested capillary tubes, of $0.55 \mathrm{~mm}$ and $0.6 \mathrm{~mm}$ diameter respectively 
Table 1: Instrumentation and its corresponding uncertainty

\begin{tabular}{|c|c|}
\hline Temperatures & Uncertainty \\
\hline Water inlet temperature & $\pm 0.07^{\circ} \mathrm{C}$ \\
\hline Water outlet temperature & $\pm 0.07{ }^{\circ} \mathrm{C}$ \\
\hline Refrigerant inlet condenser temperature & $\pm 0.078{ }^{\circ} \mathrm{C}$ \\
\hline Refrigerant outlet condenser temperature & $\pm 0.2{ }^{\circ} \mathrm{C}$ \\
\hline Capillary tube inlet & $\pm 0.07^{\circ} \mathrm{C}$ \\
\hline \multicolumn{2}{|l|}{ Pressures } \\
\hline Condensation pressure & \pm 0.04 bar \\
\hline Evaporation pressure & \pm 0.078 bar \\
\hline \multicolumn{2}{|l|}{ Mass flow rates } \\
\hline Water mass flow rate & $\pm 0.1 \%$ of rate \\
\hline Refrigerant mass flow rate & $\pm 0.25 \%$ of rate \\
\hline \multicolumn{2}{|l|}{ Power } \\
\hline Compressor power & $\pm 1.2 \mathrm{~W}$ \\
\hline
\end{tabular}


Table 2: Parameters of the different experimental campaigns

\begin{tabular}{lcccc}
\hline $\begin{array}{l}\text { Experimental } \\
\text { campaigns }\end{array}$ & $\mathbf{1}$ & $\mathbf{2}$ & $\mathbf{3}$ & $\mathbf{4}$ \\
\hline Condenser & air & water & water & air \\
$\begin{array}{l}\text { Capillary tube }(\mathrm{mm}) \\
\begin{array}{l}\text { Compressor speed } \\
\text { (rpm) }\end{array}\end{array}$ & 0.6 & 0.6 & 0.55 & $0.55 / 0.6$ \\
$\begin{array}{l}\text { Refrigerant charge }(\mathrm{g}) \\
\text { From } 74.5 \text { to } 90\end{array}$ & 1600 & 64 & $1800-2500-3500$ & 2900 \\
\hline
\end{tabular}

